\title{
Mesogenic copper(II) complexes with [1,2,3]-triazole-based bidentate Schiff bases
}

\author{
GUAN-YEOW YEAP* and BOON-TECK HENG \\ Liquid Crystal Research Laboratory, School of Chemical Sciences, Universiti Sains Malaysia, 11800 Minden, \\ Penang, Malaysia \\ e-mail: gyyeap@usm.my
}

MS received 25 May 2013; revised 26 September 2013; accepted 29 September 2013

\begin{abstract}
The first mesogenic Cu(II) complex with [1,2,3]-triazole-based bidentate Schiff bases with flexible terminal alkyl chain, $\mathrm{C}_{\mathrm{n}} \mathrm{H}_{2 \mathrm{n}+1}$ (even parity of $\mathrm{n}=10-18$ ) has been successfully synthesized. The heterocyclic triazole core was introduced into the target compound through the click reaction between azidoalkane and propargyl aldehyde. All the uncoordinated ligands and target complexes were characterized by elemental analysis, FT-IR, ${ }^{1} \mathrm{H}-\mathrm{NMR}$ and UV-visible spectroscopic techniques. The observation under the polarized light and differential scanning calometry (DSC) shows that the triazole-based ligands exhibit unstable SmA phase which are not reproducible upon subsequent heating and cooling. Interestingly, the whole homologues of $\mathrm{Cu}(\mathrm{II})$ complexes show exclusively stable focal conic fan-shaped texture characteristic of SmA phase. This can be ascribed to the presence of $\mathrm{Cu}-\mathrm{N}$ and $\mathrm{Cu}-\mathrm{O}$ coordination modes which enhance the collinearity and molecular anisotropy. On the other hand, the $\mathrm{Cu}$ (II) complexes are thermally more stable as compared to their corresponding ligands.
\end{abstract}

Keywords. $\mathrm{Cu}(\mathrm{II})$ complexes; smectic A; click reaction; triazole; Schiff bases.

\section{Introduction}

Liquid crystals have been known for more than a decade but the classes of chemical compounds capable of exhibiting liquid crystal properties have increased significantly only in the last twenty years. For example, metal containing liquid crystal which is also known as metallomesogen have received great attention leading to systematic research and development. ${ }^{1}$ Generally, the metallomesogens can be referred to coordination compounds containing mesogenic or non-mesogenic ligands. ${ }^{2}$ Metals which are used for metallomesogen are cations, for instances, silver(I), rhodium(I), iridium(I), nickel(II), copper(II), palladium(II) and platinum(II) ions. ${ }^{3}$ These cations coordinate to ligands forming linear or square planar complexes. Salicylaldimine is one of the bidentate ligands which have been extensively studied in coordination compounds. ${ }^{3}$

The liquid crystal behaviour of these metal-ligand complexes are claimed to be more prominent than the free ligands owing to the advantages of combining the properties of these ligands with those of the transition metal. For example, the presence of metal ions induces

*For correspondence the conversion from non-mesogenic ligands to mesogenic complexes. ${ }^{3-7}$ Besides, the resulting metal complexes are more polarizable and more suitably oriented for the fortification properties. Such metallomesogens combine the unique properties of liquid-crystalline anisotropic fluids with the electronic and optical properties of metal complexes. ${ }^{5}$

Since the metal ions are also known to have various geometries, the ultimate metallomesogens can probably give rise to different geometrical shapes which may not be obtained in conventional organic liquid crystals. ${ }^{8,9}$ Furthermore, metallomesogens have extra properties such as its richness in oxidation state, colour, magnetism possessed by metal ions and redox behaviour. ${ }^{8,9}$

On the other hand, the coordination of organic liquid crystal to metal centre can also cause a dramatic effect on the thermal behaviour of the organic liquid crystal such as the mesophase modification or suppression. ${ }^{10}$ These phenomena can result in changes in polarizability, molecular anisotropy, modification of the polar or dipolar characteristics and so on. ${ }^{10}$

In this paper, the 1, 2, 3-triazole core system is introduced in metallomesogens. The five-membered [1, 2, $3]$-triazole ring is formed by copper catalysed [3+ 2] dipolar cycloaddition reaction between an organic azides and terminal alkynes, which is also known as 'click reaction'. ${ }^{11}$ This heterocyclic five-membered ring 
is of great importance as core units in thermotropic liquid crystals due to their ability to increase molecular dipoles and dielectric anisotropy combined with changes in the molecular shape. ${ }^{11,12}$ Furthermore, the incorporation of heteroatoms can result in considerable changes in the physical properties of corresponding liquid-crystalline phases as the nitrogen atoms in the ring are more polarizable than carbon. ${ }^{12}$ It is also wellknown that 1,2,3-triazoles have been used as fungicides, herbicides, light stabilizers, fluorescent whiteners, optical brightening agents, corrosion inhibitors and photostabilizers for fibres, plastics or dyes. ${ }^{12,13}$ However, to the best of our knowledge, the study on the relationship between the structures and mesomorphic properties of 1,2,3-triazole-based metallomesogen has remained scarce until now.

\section{Experimental}

\subsection{Materials}

2,4-Dihydroxybenzaldehyde and propargyl bromide were purchased from TCI (Tokyol Chemical Industry) while sodium bicarbonate was obtained from R\&M-Chemicals. Copper(II) sulphate pentahydrate and sodium ascorbate were obtained from Qrec-Chemicals and Sigmal Aldrich, respectively. 1Bromodecane, 1-bromododecane, 1-bromotetradecane, 1-bromohexadecane and 1-bromooctadecane were purchased from Merck whereas 4-fluoroaniline and copper(II) acetate dihydrate were purchased from Acros-Chemical. All reagents are used without further purification.

\subsection{Physical measurement}

The chemical structures of intermediates and target materials were studied by Perkin Elmer 2000-FTIR spectrophotometer in the frequency range $4000-400 \mathrm{~cm}^{-1}$ with sample prepared in $\mathrm{KBr}$ discs. The Brucker Avance $300 \mathrm{MHz}$ ultrashield spectrometers equipped with ultrashield magnets was used to obtain the ${ }^{1} \mathrm{H}$ NMR spectra. Deuterated chloroform $\left(\mathrm{CDCl}_{3}\right)$ and dimethysulphoxide (DMSO- $d_{6}$ ) were used as solvent and TMS as internal standard. Thin-layer chromatography was performed with TLC sheets coated with silica and spots were detected by UV irradiation. The phase transition temperatures and phase transition enthalpy values were measured by using a Seiko DSC6200R calorimeter with the heating and cooling rate of $\pm 5^{\circ} \mathrm{C}$. The liquid crystal textures of all compounds were observed by Carl Zeiss Axioskop 40 polarizing microscope equipped with a Linkam LTS 350 hot stage and TMS94 temperature controller. The samples studied by optical microscope were prepared in thin film sandwiched between glass slide and cover. The Elemental $(\mathrm{C}, \mathrm{H}$ and $\mathrm{N})$ analysis were carried out using a Perkin Elmer 2400 LS Series CHNS/O analyzer. UV-visible spectra were recorded on a Perkin Elmer, Lambda 25 $\mathrm{UV} / \mathrm{Vis}$ spectrometer.

\subsection{Synthesis of 2-hydroxy-4-(prop-2-ynyloxy)benzal- dehyde, 1}

To a mixture containing $5 \mathrm{~g} \quad(36 \mathrm{mmol})$ of $2,4-$ dihydroxybenzaldehyde, catalytic amount of potassium iodide and 1 equimolar of sodium bicarbonate in acetone, 1 equimolar of propargyl bromide was added. The reaction mixture was heated for overnight. The reaction mixture was then filtered and the filtrate was evaporated to dryness. The precipitate thus obtained was washed with distilled water and purified by column chromatography eluting with a mixture of chloroform and hexane $(\mathrm{V} / \mathrm{V}, 1 / 1)$. Evaporation of the solvents gave the product as a white solid.

\subsection{Synthesis of 1-Azidoalkane}

A mixture containing $6 \mathrm{~g}$ of 1-bromoalkane and 2 equimolar of sodium azide in dimethylformide, DMF was heated overnight at $70^{\circ} \mathrm{C}$. The reaction mixture was then filtered and the filtrate was extracted twice with dichloromethane, DCM $(50 \mathrm{ml})$. The extracted solution was evaporated at room temperature to give the yellow liquid product.

\subsection{Synthesis of 4-((1-alkyl-1H-1,2,3-triazol-4-yl) methoxy)-2-hydroxybenzaldehyde, 2}

Compound 1 (100 mmol) and 1-azidoalkane (100 mol) in DMF was treated with $20 \mathrm{~mol} \%$ of $\mathrm{Cu}_{\mathrm{SO}} \cdot 5 \mathrm{H}_{2} \mathrm{O}$ in DMF and $20 \mathrm{~mol} \%$ sodium ascorbate in minimum amount of water. The reaction mixture was stirred at room temperature for $24 \mathrm{~h}$. The mixture was then poured into cold water and the resulting yellow precipitate was then filtered by using Buchner funnel. The isolated compound thus obtained was recrystallized several times from ethanol.

\subsection{Synthesis of [1,2,3]-triazole-based bidentate} ligands, $\mathbf{3}$

Compound 2 (100 mmol) was dissolved in ethanol in a round bottom flask. 4-Flouroaniline was dissolved in 
ethanol and then added dropwise to the mixture. The resulting mixture was refluxed for $6 \mathrm{~h}$ under continuous stirring. The mixture solution was then concentrated by evaporated out the ethanol at room temperature and the precipitate thus obtained was recrystallized from ethanol to yield the desired product.

The yields and the elemental analytical data for ligands $\mathbf{3 a}-\mathbf{3 e}$ are shown as follows:

(3a): Yellow, yield 43\%. Elemental analysis $/ \%$ : Found C 69.21, H 7.34, N 12.33; calculated $\left(\mathrm{C}_{26} \mathrm{H}_{33} \mathrm{FN}_{4} \mathrm{O}_{2}\right)$, C 69.00, H 7.35, N 12.30. IR (KBr) $v_{\max } / \mathrm{cm}^{-1}: 1247$ (C-O ether), 1283 (C-O phenolic), $1571(\mathrm{C}=\mathrm{C}), 1626$ $(\mathrm{C}=\mathrm{N}), 2916-2848$ (C-H alkyl), $3441(\mathrm{O}-\mathrm{H}) .{ }^{1} \mathrm{H}$ NMR (300 MHz, $\left.\mathrm{CDCL}_{3}\right), \delta$ (ppm): 0.89 (t, 3H, $\mathrm{CH}_{3}, J=$ $6.9 \mathrm{hz}), 1.33-1.95\left(\mathrm{~m}, 16 \mathrm{H}, \mathrm{CH}_{2}\right), 4.38\left(\mathrm{t}, 2 \mathrm{H}, \mathrm{OCH}_{2}\right.$, $J=7.5 \mathrm{hz}), 5.26\left(\mathrm{~s}, 2 \mathrm{H}, \mathrm{OCH}_{2}\right), 6.59-6.62(\mathrm{~m}, 2 \mathrm{H}, \mathrm{Ar}-$ $\mathrm{H}), 7.11(\mathrm{~d}, 2 \mathrm{H}, \mathrm{Ar}-\mathrm{H}, J=8.7 \mathrm{hz}), 7.24(\mathrm{~d}, 2 \mathrm{H}, \mathrm{Ar}-\mathrm{H}$, $J=8.7 \mathrm{hz}$ ), 7.30 (d, 1H, Ar-H, $J=8.4 \mathrm{hz}), 7.65$ (s, $1 \mathrm{H}$, $\mathrm{N}-\mathrm{CH}), 8.52$ (s, 1H, N=CH), 13.6 (s, 1H, Ar-OH).

(3b): Yellow, yield 55\%. Elemental analysis/\% : Found C 70.19, H 7.81, N 11.65; calculated $\left(\mathrm{C}_{28} \mathrm{H}_{37} \mathrm{FN}_{4} \mathrm{O}_{2}\right)$, C 69.97, H 7.76, N 11.66. IR (KBr) $v_{\max } / \mathrm{cm}^{-1}: 1248$ (C-O ether), 1283 (C-O phenolic), $1572(\mathrm{C}=\mathrm{C}), 1626$ $(\mathrm{C}=\mathrm{N}), 2917-2850$ (C-H alkyl), $3441(\mathrm{O}-\mathrm{H}) .{ }^{1} \mathrm{H}$ NMR $\left(300 \mathrm{MHz}, \mathrm{CDCL}_{3}\right), \delta$ (ppm): 0.89 (t, 3H, $\mathrm{CH}_{3}, J=$ $6.9 \mathrm{hz}$ ), $1.34-1.96\left(\mathrm{~m}, 16 \mathrm{H}, \mathrm{CH}_{2}\right), 4.38$ (t, $2 \mathrm{H}, \mathrm{OCH}_{2}$, $J=7.5 \mathrm{hz}), 5.25\left(\mathrm{~s}, 2 \mathrm{H}, \mathrm{OCH}_{2}\right), 6.59-6.62(\mathrm{~m}, 2 \mathrm{H}, \mathrm{Ar}-$ $\mathrm{H}), 7.10(\mathrm{~d}, 2 \mathrm{H}, \mathrm{Ar}-\mathrm{H}, J=8.7 \mathrm{hz}), 7.24(\mathrm{~d}, 2 \mathrm{H}, \mathrm{Ar}-\mathrm{H}$, $J=8.7 \mathrm{hz}), 7.30$ (d, $1 \mathrm{H}, \mathrm{Ar}-\mathrm{H}, J=8.4 \mathrm{hz}), 7.64$ (s, $1 \mathrm{H}$, $\mathrm{N}-\mathrm{CH}), 8.52(\mathrm{~s}, 1 \mathrm{H}, \mathrm{N}=\mathrm{CH}), 13.7(\mathrm{~s}, 1 \mathrm{H}, \mathrm{Ar}-\mathrm{OH})$.

(3c): Yellow, yield 53\%. Elemental analysis $/ \%$ : Found C 70.96, H 8.09, N 11.03; calculated $\left(\mathrm{C}_{30} \mathrm{H}_{41} \mathrm{FN}_{4} \mathrm{O}_{2}\right)$, C 70.84, H 8.12, N 11.01. IR (KBr) $v_{\max } / \mathrm{cm}^{-1}: 1249$ (C-O ether), 1284 (C-O phenolic), $1571(\mathrm{C}=\mathrm{C}), 1625$ $(\mathrm{C}=\mathrm{N}), 2916-2848$ (C-H alkyl), $3440(\mathrm{O}-\mathrm{H}) .{ }^{1} \mathrm{H}$ NMR (300 MHz, $\left.\mathrm{CDCL}_{3}\right), \delta$ (ppm): 0.89 (t, 3H, $\mathrm{CH}_{3}, J=$ $6.9 \mathrm{hz}), 1.33-1.95\left(\mathrm{~m}, 16 \mathrm{H}, \mathrm{CH}_{2}\right), 4.38\left(\mathrm{t}, 2 \mathrm{H}, \mathrm{OCH}_{2}\right.$, $J=7.5 \mathrm{hz}), 5.25\left(\mathrm{~s}, 2 \mathrm{H}, \mathrm{OCH}_{2}\right), 6.59-6.62(\mathrm{~m}, 2 \mathrm{H}, \mathrm{Ar}-$ $\mathrm{H}), 7.10$ (d, 2H, Ar-H, J = 8.7 hz), 7.24 (d, 2H, Ar-H, $J=8.7 \mathrm{hz}), 7.31$ (d, 1H, Ar-H, $J=8.4 \mathrm{hz}), 7.65(\mathrm{~s}, 1 \mathrm{H}$, $\mathrm{N}-\mathrm{CH}), 8.51(\mathrm{~s}, 1 \mathrm{H}, \mathrm{N}=\mathrm{CH}), 13.7(\mathrm{~s}, 1 \mathrm{H}, \mathrm{Ar}-\mathrm{OH})$.

(3d): Yellow, yield 49\%. Elemental analysis/\% : Found C 71.96, $\mathrm{H}$ 8.50, N 10.49; calculated $\left(\mathrm{C}_{32} \mathrm{H}_{45} \mathrm{FN}_{4} \mathrm{O}_{2}\right)$, C 71.61, H 8.45, N 10.44. IR (KBr) $v_{\max } / \mathrm{cm}^{-1}: 1249$ (C-O ether), 1283 (C-O phenolic), $1570(\mathrm{C}=\mathrm{C}), 1625$ $(\mathrm{C}=\mathrm{N}), 2916-2849$ (C-H alkyl), $3441(\mathrm{O}-\mathrm{H}) .{ }^{1} \mathrm{H}$ NMR (300 MHz, $\left.\mathrm{CDCL}_{3}\right), \delta$ (ppm): 0.89 (t, 3H, $\mathrm{CH}_{3}, J=$ $6.9 \mathrm{hz}), 1.33-1.96\left(\mathrm{~m}, 16 \mathrm{H}, \mathrm{CH}_{2}\right), 4.37$ (t, $2 \mathrm{H}, \mathrm{OCH}_{2}$, $J=7.5 \mathrm{hz}), 5.25\left(\mathrm{~s}, 2 \mathrm{H}, \mathrm{OCH}_{2}\right), 6.59-6.63(\mathrm{~m}, 2 \mathrm{H}$, Ar-H), 7.10 (d, 2H, Ar-H, $J=8.7$ hz), 7.24 (d, 2H,
$\operatorname{Ar}-\mathrm{H}, J=8.7 \mathrm{hz}), 7.31(\mathrm{~d}, 1 \mathrm{H}, \operatorname{Ar}-\mathrm{H}, J=8.4 \mathrm{hz})$, $7.65(\mathrm{~s}, 1 \mathrm{H}, \mathrm{N}-\mathrm{CH}), 8.51(\mathrm{~s}, 1 \mathrm{H}, \mathrm{N}=\mathrm{CH}), 13.7(\mathrm{~s}, 1 \mathrm{H}$, $\mathrm{Ar}-\mathrm{OH})$.

(3e): Yellow, yield 56\%. Elemental analysis $/ \%$ : Found C 72.58, $\mathrm{H}$ 8.73, N 9.90; calculated $\left(\mathrm{C}_{34} \mathrm{H}_{49} \mathrm{FN}_{4} \mathrm{O}_{2}\right)$, $\mathrm{C} 72.31, \mathrm{H}$ 8.74, N 9.92. IR (KBr) $v_{\max } / \mathrm{cm}^{-1}: 1248$ (C-O ether), 1283 (C-O phenolic), $1571(\mathrm{C}=\mathrm{C}), 1626$ $(\mathrm{C}=\mathrm{N}), 2916-2848$ (C-H alkyl), $3442(\mathrm{O}-\mathrm{H}) .{ }^{1} \mathrm{H}$ NMR $\left(300 \mathrm{MHz}, \mathrm{CDCL}_{3}\right), \delta$ (ppm): 0.89 (t, 3H, $\mathrm{CH}_{3}, J=$ $6.9 \mathrm{hz}$ ), 1.32-1.95 (m, 16H, $\left.\mathrm{CH}_{2}\right), 4.38$ (t, $2 \mathrm{H}, \mathrm{OCH}_{2}$, $J=7.5 \mathrm{hz}), 5.26\left(\mathrm{~s}, 2 \mathrm{H}, \mathrm{OCH}_{2}\right), 6.59-6.62(\mathrm{~m}, 2 \mathrm{H}, \mathrm{Ar}-$ $\mathrm{H}), 7.11$ (d, 2H, Ar-H, $J=8.7 \mathrm{hz}), 7.24$ (d, 2H, Ar-H, $J=8.7 \mathrm{hz}$ ), 7.29 (d, 1H, Ar-H, $J=8.4 \mathrm{hz}), 7.65$ (s, 1H, $\mathrm{N}-\mathrm{CH}), 8.52$ (s, 1H, N=CH), 13.6 (s, 1H, Ar-OH).

\subsection{Synthesis of copper(II) complexes 4}

An ethanolic solution of copper(II) acetate dihydrate $(1.0 \mathrm{mmol})$ was added dropwise to a hot ethanolic solution $(50 \mathrm{ml})$ of ligands $3(1.0 \mathrm{mmol})$ in round bottom flask. The mixture was refluxed for $6 \mathrm{~h}$ and then cooled to room temperature. The dark brown precipitate was collected by filtration and washed with hot ethanol.

The yields and the elemental analytical data for complexes $\mathbf{4 a - 4 e}$ are shown as follows:

(4a): Dark brown, yield 83\%. Elemental analysis/\%: Found C 64.49, H 6.64, N 11.55; calculated $\left(\mathrm{C}_{52} \mathrm{H}_{64} \mathrm{CuF}_{2}\right.$ $\left.\mathrm{N}_{8} \mathrm{O}_{4}\right), \mathrm{C}$ 64.61, H 6.67, N 11.59. IR (KBr) $v_{\max } / \mathrm{cm}^{-1}$ : 1250 (C-O ether), 1324 (C-O phenolic), $1590(\mathrm{C}=\mathrm{C})$, $1601(\mathrm{C}=\mathrm{N}), 2917-2850$ (C-H alkyl).

(4b): Dark brown, yield 79\%. Elemental analysis/\%: Found C 65.98, H 7.02, N 10.97; calculated $\left(\mathrm{C}_{56} \mathrm{H}_{72} \mathrm{CuF}_{2} \mathrm{~N}_{8} \mathrm{O}_{4}\right), \mathrm{C}$ 64.61, H 6.67, N 11.59. IR (KBr) $v_{\max } / \mathrm{cm}^{-1}: 1249$ (C-O ether), 1322 (C-O phenolic), $1591(\mathrm{C}=\mathrm{C}), 1601(\mathrm{C}=\mathrm{N}), 2916-2850(\mathrm{C}-\mathrm{H}$ alkyl$)$.

(4c): Dark brown, yield 88\%. Elemental analysis/\%: Found $\mathrm{C}$ 67.01, $\mathrm{H}$ 7.49, N 10.38; calculated $\left(\mathrm{C}_{60} \mathrm{H}_{80} \mathrm{CuF}_{2} \mathrm{~N}_{8} \mathrm{O}_{4}\right), \mathrm{C} 66.80, \mathrm{H}$ 7.47, N 10.39. IR (KBr) $v_{\max } / \mathrm{cm}^{-1}: 1249$ (C-O ether), 1324 (C-O phenolic), $1590(\mathrm{C}=\mathrm{C}), 1601(\mathrm{C}=\mathrm{N}), 2917-2850(\mathrm{C}-\mathrm{H}$ alkyl$)$.

(4d): Dark brown, yield 80\%. Elemental analysis/\%: Found $\mathrm{C}$ 68.04, $\mathrm{H}$ 7.83, N 9.90; calculated $\left(\mathrm{C}_{64} \mathrm{H}_{88} \mathrm{CuF}_{2} \mathrm{~N}_{8} \mathrm{O}_{4}\right), \mathrm{C} 67.73, \mathrm{H}$ 7.82, N 9.87. IR (KBr) $v_{\max } / \mathrm{cm}^{-1}: 1251$ (C-O ether), 1323 (C-O phenolic), $1590(\mathrm{C}=\mathrm{C}), 1602(\mathrm{C}=\mathrm{N}), 2916-2849$ (C-H alkyl).

(4e): Dark brown, yield 78\%. Elemental analysis/\%: Found $\mathrm{C}$ 68.75, $\mathrm{H}$ 8.10, $\mathrm{N}$ 9.42; calculated $\left(\mathrm{C}_{68} \mathrm{H}_{96} \mathrm{CuF}_{2} \mathrm{~N}_{8} \mathrm{O}_{4}\right), \mathrm{C} 68.57, \mathrm{H}$ 8.12, N 9.41. IR (KBr) 
$v_{\max } / \mathrm{cm}^{-1}: 1250$ (C-O ether), 1324 (C-O phenolic), $1591(\mathrm{C}=\mathrm{C}), 1602(\mathrm{C}=\mathrm{N}), 2917-2850$ (C-H alkyl).

\section{Result and discussion}

\subsection{Synthesis}

The mesogenic $\mathrm{Cu}(\mathrm{II})$ complexes $\mathbf{4 a}-\mathbf{4 e}$ and their bidentate ligands $\mathbf{3 a} \mathbf{a}-\mathbf{3 e}$ were prepared through the synthetic route as described in scheme 1 . The intermediate $[1,2,3]$-triazole ring compound was synthesized from the $\mathrm{Cu}(\mathrm{I})$ catalysed 'click reaction' of 1-azidoalkane $\left(\mathrm{C}_{\mathrm{n}} \mathrm{H}_{2 \mathrm{n}+1} \mathrm{~N}_{3} ; \mathrm{n}=10,12,14,16\right.$ and 18) and 2-hydroxy- 4-(prop-2-ynyloxy)benzaldehyde. The triazole derivative thus obtained was subjected to condensation reaction with aromatic amine to yield the target Schiff bases 3a-3e. Finally, the reactions between $\mathbf{3 a}-\mathbf{3 e}$ with $\mathrm{Cu}$ (II) acetate dihydrate was carried out to form $\mathrm{Cu}$ (II) complexes $\mathbf{4 a}-\mathbf{4 e}$ as dark brown solids. The chemical structure of the target ligands and their corresponding complexes were elucidated by FT-IR, ${ }^{1} \mathrm{H}-\mathrm{NMR}$, UV-visible spectrometer and elemental analysis.

The carbon, hydrogen and nitrogen composition for $\mathrm{Cu}$ (II) complexes $\mathbf{4 a}-\mathbf{4 e}$ were determined via the $\mathrm{CHN}$ microanalysis which were then compared with the calculated values. The results showed that the percentages
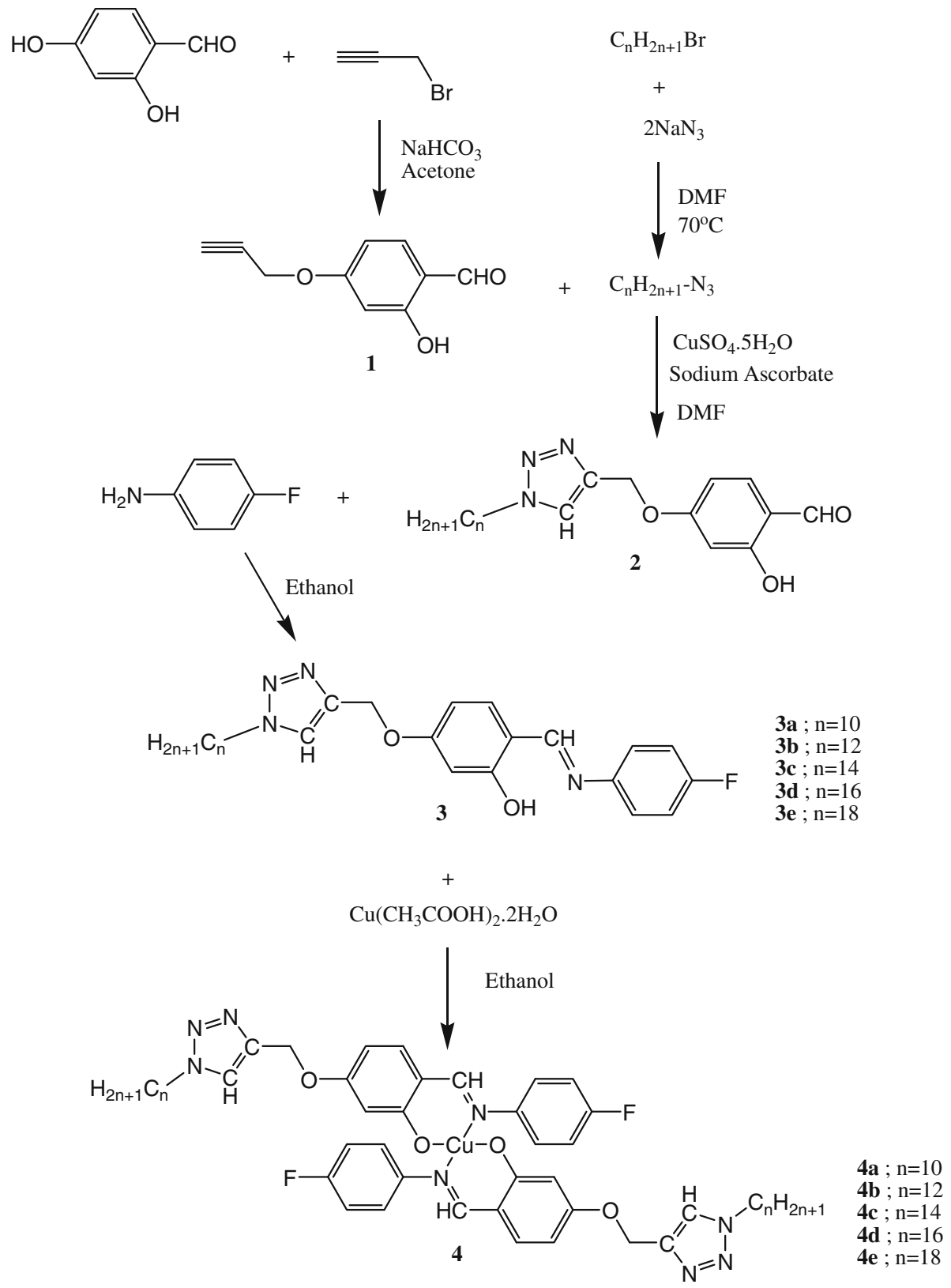

Scheme 1. Synthetic routes toward formation of ligands $\mathbf{3 a}-\mathbf{3 e}$ and $\mathrm{Cu}(\mathrm{II})$ complexes $\mathbf{4 a}-\mathbf{4 e}$. 


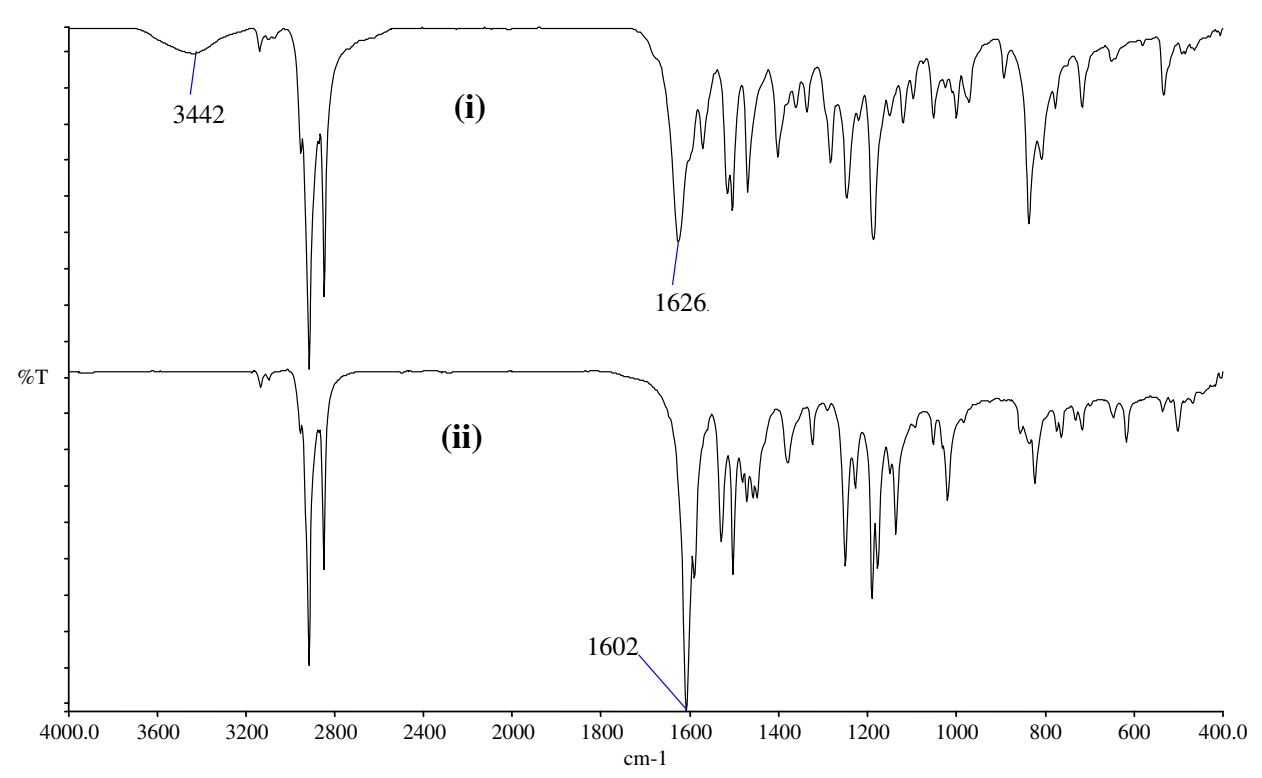

Figure 1. Representative IR spectra of (i) ligand $\mathbf{3 e}$ and (ii) $\mathrm{Cu}(\mathrm{II})$ complex $\mathbf{4 e}$.

of $\mathrm{C}, \mathrm{H}$ and $\mathrm{N}$ in the respective complexes are in agreement with its empirical formula of which the ratio of ligand: $\mathrm{Cu}$ is $2: 1$.

Based on the FT-IR spectra of ligands $\mathbf{3 a}-\mathbf{3 e}$, a strong band observed at $1625-1626 \mathrm{~cm}^{-1}$ is assigned to the stretching of imine, $\mathrm{C}=\mathrm{N}$ group. ${ }^{14-16}$ The presence of the $\mathrm{C}=\mathrm{N}$ absorption and the absence of $\mathrm{N}-\mathrm{H}$ absorption bands of 4-aminoazobenzene at $3473-3382 \mathrm{~cm}^{-1}$ indicates the formation of the desired Schiff base linkage. A strong band at $2848-2917 \mathrm{~cm}^{-1}$ can be assigned to the stretching vibration of $\mathrm{C}-\mathrm{H}$ bond from alkoxy chain. The band with strong intensity in the spectra at the range of $1247-1249 \mathrm{~cm}^{-1}\left(\mathrm{O}-\mathrm{CH}_{2}\right)$ can be ascribed to the ether group. ${ }^{17} \mathrm{~A}$ medium band at the frequency of $1570-1572 \mathrm{~cm}^{-1}$ can be attributed to the $\mathrm{C}=\mathrm{C}$ stretching in the phenyl ring. ${ }^{16}$ The broad band at 3440$3441 \mathrm{~cm}^{-1}$ can be assigned to the stretching frequency of $\mathrm{O}-\mathrm{H}$ group whereas the stretching of the phenolic $\mathrm{C}-\mathrm{O}$ is observed as a medium band at the stretching frequency of $1283-1284 \mathrm{~cm}^{-1} \cdot{ }^{18-23}$

Coordination of the ligands $\mathbf{3 a}-\mathbf{3 e}$ to $\mathrm{Cu}(\mathrm{II})$ ion involves a salicylidene fragment and imine group. The corresponding changes can be described by comparing the relevant IR bands associated with $\mathbf{3 e}$ and $\mathbf{4 e}$ (figure 1). The strong band observed at 1601$1602 \mathrm{~cm}^{-1}$ corresponds to the stretching of imine $\mathrm{C}=\mathrm{N}$. The $\mathrm{C}=\mathrm{N}$ frequency in the complex is shifted to a lower stretching frequenct by $24-25 \mathrm{~cm}^{-1}$ as compared to free ligands $\mathbf{3 a}-\mathbf{3 e}$. This observation is due to the reduction in the bond order of $\mathrm{C}=\mathrm{N}$ bond and hence suggested the coordination of $\mathrm{N}$ atom from the ligands to the centre metal atoms. ${ }^{15,21-27}$ Besides, the disappearance of the $\mathrm{O}-\mathrm{H}$ band of free ligands in IR spectruam for $\mathrm{Cu}(\mathrm{II})$ complexes indicates that the $\mathrm{OH}$ group is deprotonated to form $\mathrm{O}^{-}$ion which entails the formation of new $\mathrm{Cu}$ O coordination mode. ${ }^{15,21-27}$ Furthermore, the stretching vibration of phenolic $\mathrm{C}-\mathrm{O}$ is shifted to a higher frequency $\left(1322-1324 \mathrm{~cm}^{-1}\right)$ which can support the coordination of $\mathrm{O}^{-}$to $\mathrm{Cu}$ (II) ion. ${ }^{18,22,23,28}$ The other major bands at $2849-2917 \mathrm{~cm}^{-1}$ can be assigned to the stretching frequency of $\mathrm{C}-\mathrm{H}$ bond from alkoxy chain. The band with strong intensity in the IR spectra at $1249-1251 \mathrm{~cm}^{-1}$ is assignable to the stretching of the $\mathrm{C}-\mathrm{O}$ ether group.

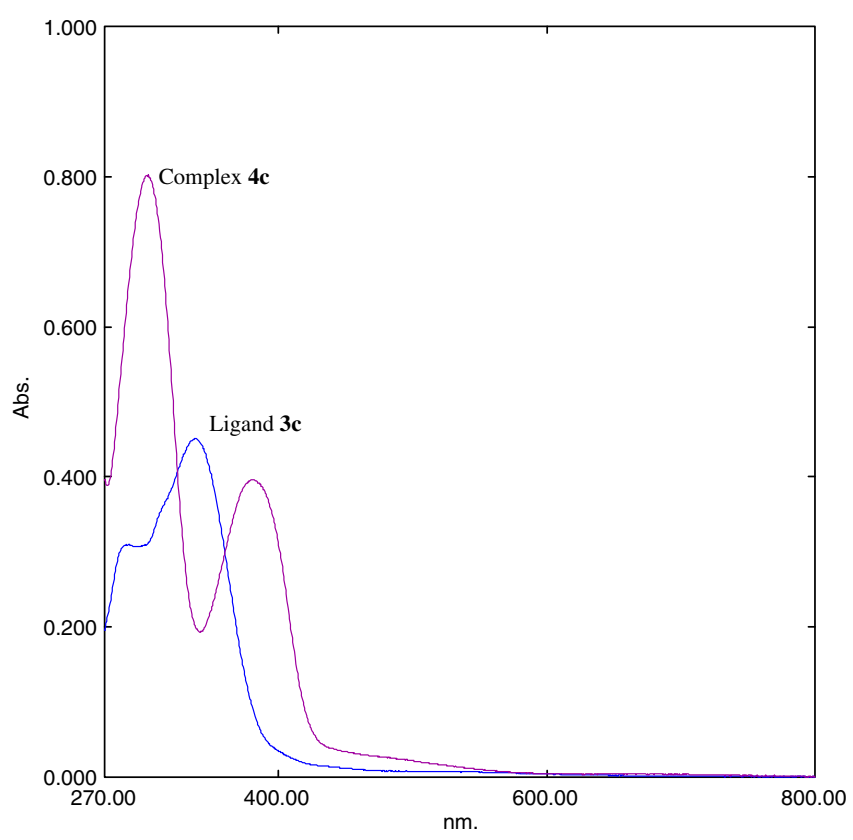

Figure 2. UV-visible spectra for ligand $\mathbf{3 c}$ and $\mathrm{Cu}(\mathrm{II})$ complex 4c. 
Table 1. UV-visible data for ligands $\mathbf{3 a}-\mathbf{3 e}$ and complexes $4 a-4 e$.

\begin{tabular}{lcc}
\hline & \multicolumn{2}{c}{ Absorption maximun,nm } \\
\cline { 2 - 3 } Compounds & $\pi-\pi^{*}$ & $n-\pi^{*}$ \\
\hline 3a & 288 & 338 \\
$\mathbf{4 a}$ & 303 & 379 \\
3b & 289 & 338 \\
$\mathbf{4 b}$ & 302 & 382 \\
3c & 288 & 338 \\
$\mathbf{4 c}$ & 303 & 379 \\
3d & 289 & 337 \\
4d & 301 & 381 \\
3e & 287 & 338 \\
4e & 303 & 380 \\
\hline
\end{tabular}

The magnetic susceptibility measurement for all $\mathrm{Cu}$ (II) metal complexes, $\mathbf{4 a - 4 e}$, in which the electronic configuration is $d^{9}$, show that these complexes are paramagnetic and their ${ }^{1} \mathrm{H}$ NMR spectra displayed only the broad signals assignable to the alkyl group as all of these proton signals are in close proximity. However, the signal for the paramagnetic $\mathrm{Cu}(\mathrm{II})$ centre is not detectable. The electronic spectra of the ligands $\mathbf{3 a}-$ $3 \mathbf{e}$ and their $\mathrm{Cu}$ (II) complexes were recorded in chloroform. Figure 2 shows the electronic spectra for ligands $\mathbf{3 c}$ and $\mathrm{Cu}$ (II) complex 4c. The UV-visible absorption spectra of the ligands consist of an intense band at 337$338 \mathrm{~nm}$ which can be related to $n-\pi *$ transition of the non-bonding valence shell electron pairs from the ligands. Another weak band at $287-288 \mathrm{~nm}$ in the higher energy region can be attributed to the $\pi-\pi *$ transition of benzene rings. Upon complexation with $\mathrm{Cu}(\mathrm{II})$ ion, these bands are red shifted to the longer wavelength (figure 2). The expected characteristic of the $\mathrm{d}-\mathrm{d}$ transitions in the visible region at about $600 \mathrm{~nm}$ for the complexes were not detectable even in the concentrated solutions. This observation is due to the forbidden transition of the highly symmetrical $\mathrm{Cu}$ (II) complexes. The UV-visible data are summarized in table 1 . All of these

Table 2. Phase transition temperature $\left({ }^{\circ} \mathrm{C}\right)$ and associated enthalpy $(\mathrm{kJ} / \mathrm{mol})$ of ligands $\mathbf{3 a}-\mathbf{3 e}$.

\begin{tabular}{|c|c|c|c|c|c|c|}
\hline Ligands & & $\mathrm{Cr}_{1}$ & & $\mathrm{Cr}_{2}$ & & I \\
\hline \multirow[t]{2}{*}{$3 \mathbf{a}$} & Heating & - & $81.8(2.4)$ & - & $115.7(16.0)$ & - \\
\hline & Cooling & - & & & $109.7(-12.8)$ & - \\
\hline \multirow[t]{2}{*}{ 3b } & Heating & - & 80.7 (8.1) & - & $115.0(22.9)$ & - \\
\hline & Cooling & - & & & $85.0(-3.3)$ & - \\
\hline \multirow[t]{2}{*}{$3 c$} & Heating & - & $79.0(2.6)$ & - & $118.8(24.8)$ & - \\
\hline & Cooling & - & & & $105.3(-26.3)$ & - \\
\hline \multirow[t]{2}{*}{ 3d } & Heating & - & $88.6(7.1)$ & & $116.8(26.3)$ & - \\
\hline & Cooling & - & & & $101.6(-38.9)$ & - \\
\hline \multirow[t]{2}{*}{$3 e$} & Heating & - & $90.9(3.7)$ & & $115.9(42.5)$ & - \\
\hline & Cooling & - & & & $97.15(-45.0)$ & - \\
\hline
\end{tabular}

$\mathrm{Cr}_{1}$, crystal 1; $\mathrm{Cr}_{2}$, crystal 2; I, isotropic.

Table 3. Phase transition temperature $\left({ }^{\circ} \mathrm{C}\right)$ and associated enthalpy $(\mathrm{kJ} / \mathrm{mol})$ of complexes $4 \mathbf{a}-\mathbf{4 e}$.

\begin{tabular}{|c|c|c|c|c|c|c|}
\hline Complexes & & $\mathrm{Cr}$ & & SmA & & I \\
\hline \multirow[t]{2}{*}{$4 \mathbf{a}$} & Heating & - & & & $157.9(36.0)$ & - \\
\hline & Cooling & - & $111.1(-8.0)$ & - & $127.1^{\mathrm{a}}$ & - \\
\hline \multirow[t]{2}{*}{$4 b$} & Heating & - & & & 157.5 (39.9) & - \\
\hline & Cooling & - & $96.2(-3.3)$ & - & $114.0^{\mathrm{a}}$ & - \\
\hline \multirow[t]{2}{*}{$4 c$} & Heating & - & & & 156.3 (41.4) & • \\
\hline & Cooling & - & $101.9(-18.2)$ & - & $126.6(-5.6)$ & - \\
\hline \multirow[t]{2}{*}{$4 d$} & Heating & $\bullet$ & & & $155.9(89.0)$ & - \\
\hline & Cooling & - & $107.5(-18.7)$ & - & $130.4(-6.4)$ & - \\
\hline \multirow[t]{2}{*}{$4 e$} & Heating & - & & & 154.8 (93.6) & - \\
\hline & Cooling & - & $102.5(-19.3)$ & - & $133.5(-7.1)$ & - \\
\hline
\end{tabular}

Cr, crystal; Sm A, smectic A; I; isotropic

${ }^{\text {a }}$ Denotes transition temperatures determined via polarizing microscopy, undetected via DSC 


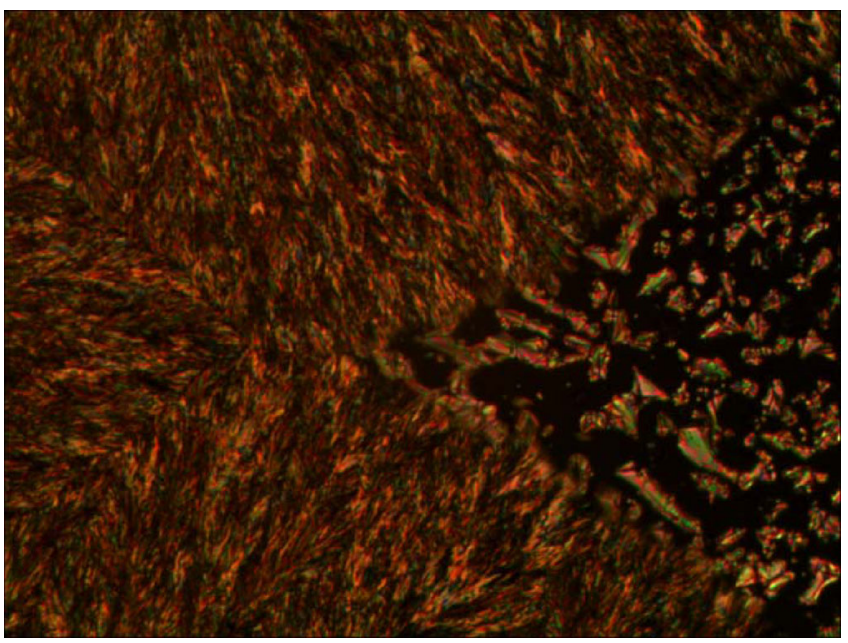

Figure 3. Photomicrograph shows the existence of battonets and crystal phase of ligand $\mathbf{3 d}$ at $101.6^{\circ} \mathrm{C}$ during the cooling process.

observations support the formation of $\mathrm{Cu}-\mathrm{O}$ and $\mathrm{Cu}-$ $\mathrm{N}$ coordination modes in which the ratio of $\mathrm{Cu}(\mathrm{II})$ to ligands is $1: 2$.

\subsection{Phase transition and mesomorphic properties of [1,2,3] triazole Schiff bases and related $\mathrm{Cu}(\mathrm{II})$ complexes}

The transition temperatures and associated enthalpies $\left(\mathrm{kJ} \mathrm{mol}^{-1}\right.$ ) obtained from differential scanning calorimetry (DSC) are tabulated in tables 2 and 3, respectively. The first cooling on ligands $\mathbf{3 a}-\mathbf{3 e}$ from isotropic liquid with transition rate of $1{ }^{\circ} \mathrm{C} \mathrm{min}{ }^{-1}$ shows the existence of battonets of SmA phase and crystal phase. Figure 3 shows that the presence of battonets is suppressed very quickly by the formation of crystal phase and these two phases occurred almost at the same time. Besides, the battonets of SmA phase is not reproducible upon subsequent heating and cooling. This phenomenon can be explained by the alkyl chain of $[1,2,3]$-triazole ring which shows non-colinearity to the rigid core segment leading to the poor mesophase stability. ${ }^{11,23}$ It also shows clearly in figure 4 that the alkyl chain attached to the triazole ring is 'out of line' with the molecular long axis and therefore reduced the

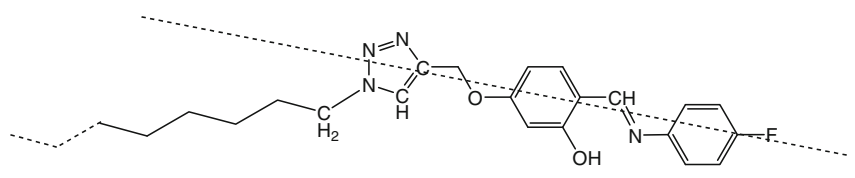

Figure 4. The molecular structure of ligand with the dotted line indicating the molecular axis.

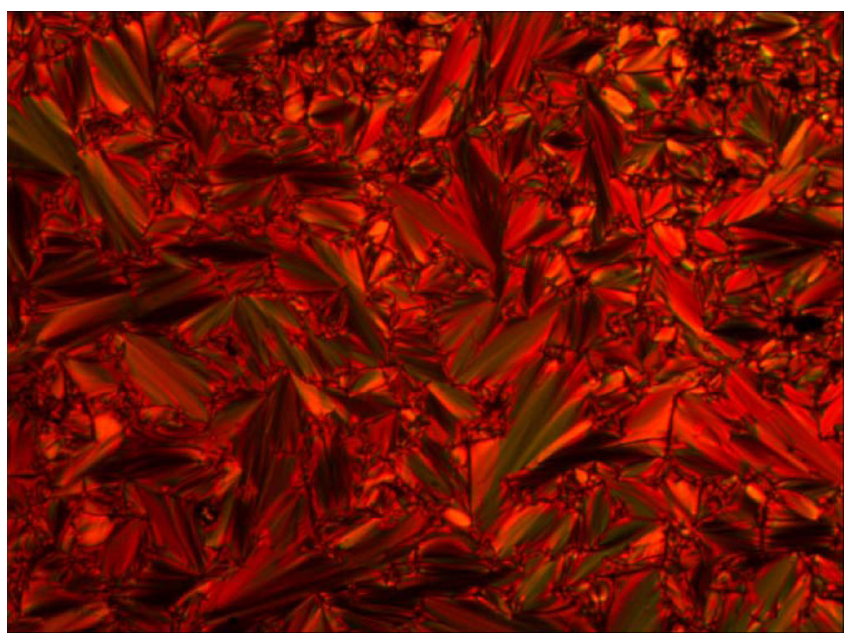

Figure 5. Photomicrograph shows the SmA phase with focal conic fan-shaped texture of complex $4 \mathbf{d}$ at $130.4^{\circ} \mathrm{C}$ during the cooling process.

molecular anisotropic and resulted in lower clearing temperature. ${ }^{23,29,30}$

Optical observation shows that the whole homologous series of $\mathrm{Cu}(\mathrm{II})$ complexes $\mathbf{4 a}-\mathbf{4 e}$ exhibit monotropic SmA phase. Upon cooling, the liquid phases of these complexes are gradually changed to the SmA phases with focal conic fan-shaped texture as illustrated in figure 5. The formation of mesophase is reproducible upon subsequent heating and cooling. The formation of stable SmA phase in complexes as compared to the free ligands can be attributed to the metal ions which increases the colinearity and thus enhances the anisotropic properties of these ligands. ${ }^{3-7}$ On the other hand, the formation of $\mathrm{Cu}$ (II) complexes $\mathbf{4 a}-\mathbf{4 e}$ can also increase the aspect ratio of aromatic core to terminal flexible chain which enhances the thermal stability of both crystal and liquid crystal phases. ${ }^{31}$

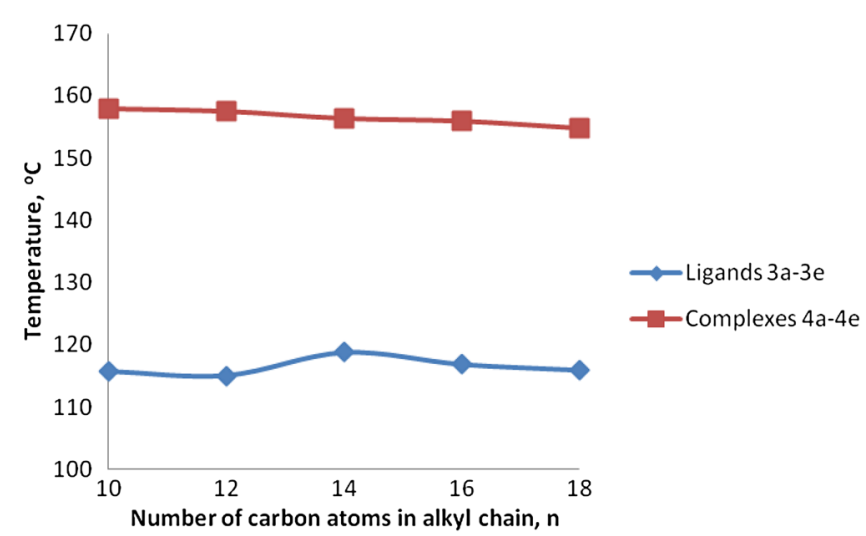

Figure 6. A plot of clearing temperature versus the number of carbon atoms in alkyl chain for the ligands $\mathbf{3 a}-\mathbf{3 e}$ and their $\mathrm{Cu}$ (II) complexes $\mathbf{4 a - 4 e}$. 
The correlation study between thermal stability of free ligands and their corresponding complexes has shown that the $\mathrm{Cu}$ (II) complexes $\mathbf{4 a - 4 e}$ are thermally more stable than free ligands 3a-3e. Figure 6 shows that the clearing temperatures of $\mathrm{Cu}$ (II) complexes increases by $37-42^{\circ} \mathrm{C}$ upon complexation. This phenomenon can be ascribed to the fact that the molecular weights as well as the number of interacting sites of $\mathrm{Cu}$ (II) complexes are higher in comparison to the ligands. ${ }^{14}$

\section{Conclusion}

A series of $\mathrm{Cu}(\mathrm{II})$ complexes derived from [1,2,3]triazole bidentate Schiff bases with various alkyl groups of even parity ( $\mathrm{n}=8-16)$ were successfully synthesized and characterized. All the $\mathrm{Cu}$ (II) complexes show monotropic SmA phase which are reproducible upon subsequent heating and cooling. The non-collinearity of the ligands has led to the formation of monotropic SmA phase with poor stability. The clearing temperatures of $\mathrm{Cu}(\mathrm{II})$ complexes are significantly higher as compared to the uncoordinated ligands and these values decrease with the increase in the length of the alkyl chain.

\section{Acknowledgements}

The first author would like to thank Universiti Sains Malaysia for the RU Grant No. 1001/PKIMIA/811159 and 1001/PKIMIA/811223.

\section{References}

1. Rezvani Z, Divband B, Abbasi A R and Nejati K 2006 Polyhedron 251915

2. Meyer E, Zucco C and Gallarlo H 1998 J. Material. 81351

3. Jung B M, Huang Y D and Chang J Y 2010 J. Liq. Cryst. 3785

4. Cardinaels T, Ramaekers J, Guillon D, Donnio B and Binnemans K 2005 J. Am. Chem. Soc. 12717602

5. Patel D B and Bhattacharya P K 2005 Mol. Cryst. Liq. Cryst. $\mathbf{4 3 2} 47$

6. Lee C K, Ling M C and Ivan Lim J B 2003 J. Chem. Soc. Dalton Trans. 24 4731-4737

7. Donnio B 2002 Curr. Opin. Colloid Interface Sci. 7 371
8. Marcos M, Omenat A, Barberá J, Durán F and Serrano J L 2004 J. Mater. Chem. 143321

9. Abe Y, Nakabayashi K, Matsukawa N, Takashima H, Iida M, Tanase T, Sugibayashi Mukai $\mathrm{H}$ and Ohta $\mathrm{K}$ 2006 Inorg. Chim. Acta. 3593934

10. Plasseraud L, Cuervo $1 \mathrm{G}$, Guillon D, Fink G S, Deschenaux R, Bruce D W and Donnio B 2002 J. Mater. 122653

11. Srividhya D, Manjunathan S, Thirumaran S and Saravanan C 2009 J. Mol. Struct. 9277

12. Gallardo H, Bortoluzzi A J and Oliveira Santos M P D 2008 Liq. Cryst. 6719

13. Gallardo H, Ely F, Bortoluzzi A J and Conte G 2005 Liq. Cryst. 32667

14. Chae H W, Kadhin O N and Choi M G 2009 J. Liq. Cryst. 3653

15. Rezvani Z, Divband B, Abbasi A R and Nejati K 2006 Polyhedron 251915

16. Yeap G Y, Hng T C, Kamil Mahmood W A, Ito M M, Youhei Y, Takanishi Y and Takezoe H 2010 Liq. Cryst. 33979

17. Pretsch E, Buhlmann P and Affolter C 2000 Structure determination of organic compound (Spring-Verlag Berlin Heidelberg, New York)

18. Mustafaa I M, Hapipaha M A, Abdullab M A and Warda T R 2009 Polyhedron 283993

19. Mahalakshmi N and Rajavel R 2011 Asian J. Biochem. Pharm. Res. 12231

20. Liu J N, Wu B W, Zhang B and Liu Y 2006 Turk. J. Chem. 3041

21. Yeap G Y, Heng B T, Kakeya M, Takeuchi D, Gorecka E and Ito M M 2011 J. Mol. Struct. 99968

22. Yeap G Y, Heng B T, Tanabe M and Takeuchi D 2011 Mol. Cryst. Liq. Cryst. 552217

23. Yeap G Y, Heng B T, Faradiana N, Zulkifly R, Ito M M, Tanabe M M and Takeuchi D 2012 J. Mol. Struct. 10121

24. Rezvani Z, Ahar L R, Nejati K and Seyedahnadian S M 2004 Acta Chim. Slov. 51675

25. Suste A and Sunjic V 1996 Liq. Cryst. 20219

26. Pucci D, Aiello I, Bellusci A, Callipari G, Crispini A and Ghedini M 2009 Mol. Cryst. Liq. Cryst. 500144

27. Nandiraju V S, Singha D, Das M and Paul M K 2002 Mol. Cryst. Liq. Cryst. 373105

28. Creavena B S, Duffa B, Egana D A, Kavanaghe K, Rosaird G, Thangellaa V R and Walsha M 2010 Inorg. Chim. Act. 3634048

29. Okamato K, Kawamura T, Sone M and Ogino K 2007 Liq. Cryst. 91001

30. Van Der Veen J, De Jue W H, Grobben A H and Boven J 1972 Mol. Cryst. Liq. Cryst. 17291

31. Yoo Y S, Im J H, Han B H, Lee M and Choi M G 2001 Bull. Korean Chem. Soc. 2212 